\title{
Intracranial pressure and the anaesthetist
}

Airway management and manipulation of the cerebral circulation are the two comerstones in preventing impending brain herniation in acutely decompensating patients. Thus, the anaesthetist will frequently play a key role in handling these patients. Aggressive management will often be highly rewarding because effective treatment for the underlying pathology can result in complete recovery.

\section{Pathophysiology of increased intracranial pressure ${ }^{1}$} The intracranial pressure (ICP) may be defined as the fluid pressure in the ventricular and lumbar subarachnoid space in a supine subject, with reference to atmospheric pressure. In normal individuals this pressure may be as high as $10 \mathrm{mmHg}$. The static ICP is a reflection of the factors involved in cerebrospinal fluid (CSF) dynamics. ${ }^{2}$ Cerebrospinal fuid is produced in the choroid plexus at a rate of 30 per cent of total CSF volume per hour. With increasing intracranial pressure, this rate of production decreases little until ICP approaches arterial pressure. Reabsorption of CSF into the dural venous sinuses, however, increases with increasing ICP. The static ICP is the pressure at which CSF formation is balanced by CSF reabsorption. Increases in ICP therefore indicate an increase in CSF production (or oedema formation), an increase in dural sinus pressure, or an increase in resistance to CSF reabsorption.

A dynamic change in ICP, that is a change in pressure that occurs after an acute change in volume of one of the intracranial compartments, is related to the elastance of the intracranial contents. When there is a space-occupying lesion, as the volume of the lesion increases, the capacity of the ICP to adapt to changes in volume diminishes. In head-injured patients, the change in pressure produced by the addition of $1.0 \mathrm{ml}$ into the CSF space has been introduced ${ }^{3}$ as a measure of elastance (volume pressure ratio, VPR). Clinically, the degree of brain shift has been found to correlate more closely with the volumepressure ratio than with the $\mathrm{ICP}{ }^{4}$

If intracranial structures maintain their nommal anatomic relationships, ICP may increase to very high levels (40-60 cm CSF) without causing neurological dysfunction. ${ }^{4}$ If increased tissue pressure within the cranium is not evenly distributed pressure gradients may cause brain shift and focal ischaemia or obstruction of CSF pathways.

Recent experimental work ${ }^{5}$ suggests that pressure gradients in the neuraxis develop in three stages. During
David P. Archer MD FRCPC

initial spatial compensation for an increased volume of one of the intracranial components there are no intercompartmental pressure gradients. As transtentorial hemiation begins, a pressure gradient develops between the supratentorial and the infratentorial compartment. Ventricular pressure at this point is approximately $20 \mathrm{mmHg}$. In the last stage (once hemiation is complete) the supratentorial pressure rises rapidly.

\section{Cerebrovascular factors and acute arterial hypertension}

Changes in systemic blood pressure between mean arterial pressures of 50 and $150 \mathrm{mmHg}$ have little effect on cerebral blood flow or volume in cerebrovascular beds that retain autoregulation. However, with many mass lesions there may be loss of autoregulation, sometimes in areas of brain much larger than the actual lesion.' In areas around neoplasms, abscesses, cerebral infarcts, and contusions, blood flow varies passively with systemic arterial pressure. In addition to causing brain engorgement, arterial hypertension will increase fluid transudation in regions of vasogenic oedema. ${ }^{6}$ Thus acute arterial hypertension may greatly increase brain bulk, causing increased brain shift and sharply increased ICP.

The significance of a transient increase in ICP is obvious. Once a transtentorial pressure gradient has developed, any increase in supratentorial volume may cause large rises in supratentorial pressure, with increased gradients leading to brain shift and acute hemiation.

\section{Intracranial pressure control}

Treatment of acute herniation depends upon reducing intracranial CSF, blood or tissue volume. The factors that determine cerebral blood volume are those that affect the vascular tone in the brain. A recently modified hydraulic model of the cerebrovascular bed ${ }^{7}$ which assigns an inflow and an outflow resistance on either side of a distensible tube (Figure 1) has been used to predict the effects on ICP of changes in the vasculature. In this model it is assumed that ICP closely approximates venous outflow pressure ( $\mathrm{Pv})$.

Department of Araesthesia, Montrcal Ncurological Hospital, McGill University, 3801 University Street, Montreal, Quebec, Canada H3A 2B4. 


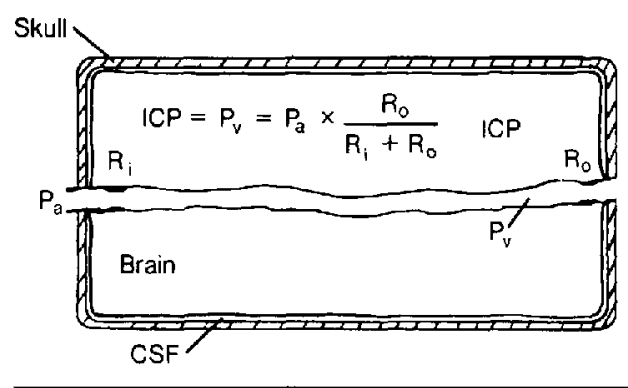

FIGURE Hydraulic model of the cerebral circulation.

Under conditions of steady flow,

$\mathrm{ICP}=\mathrm{Pv}=\mathrm{Pa} \times \frac{\mathrm{Ro}}{\mathrm{Ro}+\mathrm{Ri}}$

(Equation 1)

where $\mathrm{Pv}$ and $\mathrm{Pa}$ are the mean venous and arterial pressures, $\mathrm{Ri}$ and $\mathrm{Ro}$ are the inflow and outflow resistances respectively. From Equation 1, the ICP will vary indirectly with the inflow resistance. Although it is possible for an increase in outflow resistance to offset a decrease in inflow resistance in this model, this situation would occur only as ICP approaches arterial pressure. It therefore follows that conditions that decrease $\mathrm{Ri}$ (vasodilators) will lead to increases in ICP and CBF, while conditions that increase $\mathrm{Ri}$ (vasoconstrictors) will decrease ICP.

A major determinant of $\mathrm{Ri}$ and cerebral blood flow is the partial pressure of $\mathrm{CO}_{2}$ in the arterial blood. The effects of $\mathrm{PaCO}_{2}$ on CBF depend on the direct action of the $\left[\mathrm{H}^{+}\right]$in the cerebral interstitial fluid upon the smooth muscle of cerebral arterioles. When $\mathrm{CBF}$ is altered by changes in $\mathrm{PaCO}_{2}$, there is a non-linear correlation between $\mathrm{CBF}$ and $\mathrm{CBV}{ }^{8}$ Thus one of the cornerstones of acute ICP control is the reduction of $\mathrm{CBV}$ by acute respiratory alkalosis. Clinically both the high $\mathrm{ICP}$ and the signs of acute transtentorial herniation may be reversed by hypocapnia. ${ }^{9,10}$ Hyperventilation reduces CBF with no effect on cerebral metabolism, but when $\mathrm{PaCO}_{2}$ is lowered below $25 \mathrm{mmHg}$, increases in cerebral a-v $\mathrm{DO}_{2}$ may herald the onset of ischaemia. " Hypotension has been shown to have an additive effect in reducing CBF and increasing biochemical markers of ischaemia in hypocapnic anaesthetized dogs. ${ }^{12}$

During chronic respiratory alkalosis, CSF $\mathrm{pH}$ returns towards normal because of loss of bicarbonate from the CSF and a new equilibrium is established within 6-24 hours. ${ }^{13}$ Although the effectiveness of hypocapnia in controlling ICP may diminish during this period, a return to normoventilation will cause cerebral vasodilation. There- fore if normocapnia is desired, the patient's clinical condition or preferably his ICP should be monitored closely during the change.

The mode of ventilation is an important factor in ICP control. During controlled ventilation, efforts must be made to minimize the transmission of the increase in intrathoracic pressure to the cerebral venous circulation. A 15-30 degree head-up position will decrease the effects of intrathoracic pressure on ICP and allow $5-10 \mathrm{~cm} \mathrm{H}_{2} \mathrm{O}$ of positive end expiratory pressure (PEEP) to be applied to the airway with minimal increase in ICP. ${ }^{14}$ The published human data on this subject were reviewed by Cooper et al., ${ }^{15}$ who concluded that the application of up to $10 \mathrm{~cm} \mathrm{H}_{2} \mathrm{O}$ PEEP for the correction of hypoxaemia was not likely to affect the ICP adversely in appropriately managed patients. However, they recommended that the ICP should be monitored in patients to whom PEEP was applied to detect the occasional patient in whom it increased. Although high-frequency ventilation (HFV) has been shown to produce lesser increases in mean airway pressure than conventional ventilation, it does not appear to be advantageous in patients with high ICP. $^{16}$

\section{Tracheal intubation}

Although tracheal intubation is necessary for any prolonged ventilatory therapy, it may not be the first manoeuvre to be performed in the patient with acutely increased ICP. Airway obstruction and hypoventilation are common in decompensating patients. Reversal of the resultant hypoxia and hypercarbia can be achieved with mild hyperventilation by bag and mask and this may lead to substantial improvement before intubation. If the patient's condition permits, steps should be taken to limit the rise of ICP which occurs with tracheal intubation. Reduction of brain bulk with osmotic diuretics will produce a rapid improvement in intracranial compliance. ${ }^{3}$ Mannitol in doses of $0.25-2 \mathrm{~g} \cdot \mathrm{kg}^{-1}$ acts non-specifically to decrease ICP by removing water from brain that has normal permeability characteristics. ${ }^{17}$ If the patient has a ventriculostomy in place, then this may be used for CSF removal before intubation and also for measuring ICP.

In the absence of contraindications, good intubating conditions should be provided with thiopentone and a muscle relaxant. If succinylcholine is chosen, then an appropriate "defasciculating" dose of non-depolarizing relaxant has been shown to prevent the increase in ICP associated with the administration of succinylcholine alone. ${ }^{18}$ With the use of a barbiturate-succinylcholine sequence in patients with intracranial masses, the increase in ICP associated with endotracheal intubation has been observed to be 50 to $100 \mathrm{mmHg} .{ }^{19,20}$ These changes in ICP were accompa- 
nied by increases in mean arterial pressure such that cerebral perfusion pressure was largely unchanged. The administration of lidocaine ${ }^{21}$ or a second dose of thiopentone $e^{22}$ before intubation has been reported to blunt these rises in ICP. It is particularly important to reassess the depth of anaesthesia before intubation when a longacting muscle relaxant is used to facilitate intubation, since the effects of a sleep dose of barbiturate at induction may be wearing off. A thiopentone infusion ( $14 \mathrm{mg}$. $\mathrm{kg}^{-1} \cdot \mathrm{hr}^{-1}$ ) has been used to decrease CBF for up to one hour in spontaneously breathing patients. ${ }^{23}$

\section{Effects of anaesthetic agents on ICP}

When anaesthetizing patients with increased ICP, it is important to choose a technique suited to the control of intracranial pressure and brain swelling. Neuroleptanaesthesia using a combination of nitrous oxide, oxygen, fentanyl and droperidol combined with mild hyperventilation has been popular as it provides cxcellent neurosurgical conditions. Systemic hypertension is a common problem with neuroleptanaesthesia, and the addition of volatile agents such as halothane and isoflurane in 0.5 1 MAC doses offers both better blood pressure control and decreased patient recall. Although halothane is a potent cerebral vasodilator and has been shown to increase ICP in humans ${ }^{24}$ and to aggravate brain shift in experimental animals, ${ }^{25}$ hypocapnia induced before the agent has been added blunts the increase in ICP. ${ }^{26}$

Isoflurane has been proposed as a volatile anaesthetic superior to halothane for use in neurosurgical patients in part because ICP increases less with isoflurane than with halothane. In studies of patients with mass lesions, ICP changed little if isoflurane was added to a standard barbiturate-narcotic induction sequence in hyperventilated patients. ${ }^{27,28}$ Since these patients have usually been treated with steroids before surgery, few have critically increased ICP when anaesthesia is induced and therefore may not be ideal for observing increases in ICP. With experimentally increased ICP, three studies using cryogenic freezing lcsions to cause an intracranial mass with oedema failed to demonstrate any difference in the effect on ICP of isoflurane, halothane, and enflurane. ${ }^{29-31}$ Although brain protrusion through a craniotomy was less with isoflurane ${ }^{32}$ than with halothane, some protrusion did. occur. Grosslight et al ${ }^{33}$ noted that increases in ICP from 5-13 mmHg occurred when isoflurane was administered to hyperventilated patients with brain tumours. Also, those at risk for ICP increase could be identified by a midline shift of brain structures on the CT scan. Since increases in ICP as small as $5-10 \mathrm{mmHg}$ have been shown to be associated with the development of anisocoria, $^{25}$ isoflurane may not be completely benign in patients at risk for brain shift, particularly those who demonstrate signs of rostrocaudal deterioration despite spontancous or induced hypocapnia.

\section{Prolonged control of elevated intracranial pressure}

The benefit of controlling ICP with medical measures in conditions such as Reye's syndrome, near-drowning, and head injury remains uncertain. These patient populations are very heterogeneous and improvement in mortality and morbidity through aggressive ICP control has not been clearly demonstrated. Clinicians are in general more optimistic when the pathophysiology of the increased ICP does not involve structural brain damage (cerebral oedema following otherwise uneventful arteriovenous malformation excision) than when there is diffuse brain injury. However, completely reliable methods for selecting patients who might benefit from aggressive therapy have yet to be discovered. Recently Piatt and Schiff ${ }^{34}$ have reviewed the use of high-dose barbiturates in neurosurgery.

In summary, an aggressive approach to reverse rostrocaudal deterioration and reduce intracranial pressure is essential during the acute management of patients with treatable intracranial pathology. Methods to increase intracranial compliance should be instituted before stimuli such as endotracheal intubation are applied. If possible the use of volatile anaesthetics should be avoided in the patient at risk of increased ICP. Isoflurane may cause significant increases in ICP even in hyperventilated patients.

\section{References}

1 Plum F, Posner JB. Supratentorial lesions causing coma. In: The Diagnosis of Stupor and Coma. Philadelphia: FA Davis, 1982: 89-112.

2 Sullivar HG, Miller JD. Searle JR. An interpretation of pressure/volume interactions in the craniospinal axis Neurosurg 1980; 6: 453-62.

3 Miller $J D$, Garibi $J$. Intracranial volume-pressure studies in patients with head injury. Injury: The British Joumal of Accident Surgery 1974; $5: 265-9$

4 Miller ID. Stanek A, Langfit TW. Concepts of cerebral perfusion pressure and vascular compression during intracranial hypertension. Prog Brain Res 1972; 35: 411-32.

5 Takizawa H, Gabra-Sanders T, Miller JD. Analysis of changes in intracranial pressure and pressure-volume index at different locations in the craniospinal axis during supratentorial epidural balloon intlation. Neurosurgery 1986; 19: $1-7$.

6 Durward $Q J$, Del Maestro RF, Amacher AL, Farrar JK, The influence of systemic arterial pressure and intracranial 
pressure on the development of cerebral vasogenic edema. J Neurosurg 1983; 59: 803-9.

7 Pormoy HD, Chopp $M$. Hydraulic model of myogenic autoregulation and the ccrebrovascular bed: the effects of altering systemic arterial pressure. Neurosurg 1983; 13: 5-11.

8 Grubb RLJr, Raichle ME, Eichling JO et al. The effects of changes in $\mathrm{PaCO}_{2}$ on cerebral blood volume, blood flow and vascular mean transit time. Stroke 1974; 5: 630-8.

9 Brendler SJ, Selverstone B. Recovery from decerebration. Brain 1970; 93: 381-92.

10 Zervas $N Y$, Hedley-Whyte J. Successful treatment of cere bral herniation in five patients. N Eng! J Med 1972; 286; 1075-7.

11 Obrist WD. Genarelli TA, Segcwa $H$ et al. Relation of cerebral blood flow to neurological status and outcome in head injured patients. J Neurosurg 1979; 51: 292-300.

12 Levin RM, Zadigian ME, Hall SC. The combined effect of hyperventilation and hypotcnsion on ccrebral oxygenation in anaesthetized dogs. Can Anaesth Soc J 1980; 27: 264-73.

13 Hornbein TF, Pavlin EG. Distribution of $\mathrm{H}^{+}$and $\mathrm{HCO}_{3}{ }^{-}$ between cerebrospinal fluid and blood during respiratory alkalosis in dogs. Am J Physiol 1975; 228: 1134-40.

14 Abbushi W, Herki G. Speckner G, Birk M. The effect on ICP of PEEP-ventilation and clcvation of the upper body in patients with cerebral injuries. Anaesthetist 1980; 29 : 521-4

15 Cooper KR, Boswell PA, Choi SC. Safe use of PEEP in patients with severe head injury. J Neurosurg 1985; 63 : 552-5.

16 Grasberger RG, Spatz EL, Mortara RW, Ordeia J, Yeston $N S$. Effect of high frequency ventilation versus conven tional mechanical ventilation on ICP in head-injured dogs. J Neurosurg 1984; 60: 1214-8.

17 Marshall LF, Smith RW, Rauscher LA et al. Mannitol dose requirements in brain-injured patients. J Neurosurg 1978; 48: $169-72$

18 Stirt JA, Grosslight KR, Bedford RF, Vollmer D. Pretreatment with a defasciculating dose of metocurine prevents succinylcholine-induced increases in intracranial pressure. Anesthesiology 1986; 65: A302.

19 Misfeldt BB, Jorgensen PB, Rishoj M. The effect of nitrous oxide and halothane upon the intracranial pressure in hypocapnic patients with intracranial disorders. Br J Anaesth $1974 ; 46: 853-8$.

20 Greenbaum $R$. Anaesthesia for intracranial surgery. Br J Anaesth 1976; 48: 773.

21 Bedford RF, Winn HR, Tyson G, Park TS, Jane J. Lidocaine prevents increased ICP after endotracheal intubation. In: Shulman K (Ed.) Intracranial Pressure IV. Bcrlin: Springer-Verlag, 1980: 595.
22 Unni VKN, Johnston RA, Young HSA, MCBride RJ. Prevention of intracranial hypertension during laryngoscopy and endotracheal intubation. Br J Anaesth 1984; 56: 1219-23.

23 Cotê J, Simard D, Rouillard $M$. Repercussion sur le debit sanguin cerebral d'une perfusion de thiopental, Can Anaesth Soc J 1979; 26: 269-76.

24 Jennest WB, Barker J, Fitch Wet al. Effect of anassthesia on intracranial pressure in patients with space-occupying lesions. Lancet 1969; 1: 169.

25 Fitch $W$, McDowall DG. Effect of halothane on intracranial pressure gradients in the presence of intracranial space-occupying lesions. Br J Anaesth 1971; 43; 904-11.

26 Adams RW, Gronert GA, Sundt TM et al. Halothane, hypocapnia, and cerebrospinal fluid pressure in neurosurgery. Anaesthesia 1972; 37: 510-7.

27 Adams RW, Cucciara RF, Gronert GA, Messick JM, Michenfelder $J D$. Isoflurane and cerebrospinal fluid pressure in ncurosurgical patients. Anesthesiology 1981; 54: 97-9.

28 Campkin TV. Isoflurane and cranial extradural pressure - a study in neurosurgical patients. Br J Anaesth 1984; 56 : $1083-6$.

29 Smith AL, Marque JJ. Anesthetics and cerebral edema. Anesthesivlogy $1976 ; 45: 64-72$.

30 Scheller MS, Todd MM, Drummond JC, Zornow MH. A comparison of ICP effects of isoflurane and halothane after cryogenic brain injury in rabbits. Anesth Analg 1986; 65 : S133.

31 Scheller MS, Todd MM, Drummond JC. Hypocapnia does not alter ICP response to halothane or isofiurane following cryogenic brain injury in rabbits. Anesthesiology 1986; 65 : A346.

32 Drummond JC, Todd MM, Toutant SM, Shapiro HM Brain surface protrusion during enflurane, halothane, and isoflurane anesthesia in cats. Anesthesiology 1983; 59: 288-92.

33 Grosslight $K$, Roster R, Colohan AR, Bedford RF, 1soflurane for neuroanesthesia: risk factors for increase in intracranial pressure. Anesthesiology 1985; 63: 533-6.

34 Piatt $J H$, Schiff $S J$. High dose barbiturate therapy in neurosurgery and intensive care. Neurosurgery 1984; 15 : 427-44. 